\title{
A Study on Awareness of Bone Health among Middle Aged Women in Urban Area of Eastern Uttar Pradesh, India
}

\author{
Meenu Sirohi* and Kalpna Gupta \\ Department of Food and Nutrition, Banaras Hindu University, Varanasi, India \\ *Corresponding author
}

\begin{tabular}{|l|}
\hline Ke y w or d s \\
Bone health, \\
Calcium, Vitamin \\
D, Menopause, \\
Nutrients, \\
Osteoporosis \\
\hline Article Info \\
\hline $\begin{array}{l}\text { Accepted: } \\
\text { 26 December } 2017 \\
\text { Available Online: } \\
\text { 10 January } 2018\end{array}$ \\
\hline \hline
\end{tabular}

A B S T R A C T

After menopause several physiological and psychological changes occur among middle aged women. Among all these changes the most affected change is bone loss. After this phenomenon the absorption of calcium and vitamin $\mathrm{D}$ is reduced this affects the bone health and causes osteoporosis. Poor bone health is the leading cause of morbidity and mortality among middle aged menopausal women globally. The menopausal transition is characterized by rapid bone loss. It has been proved by various researches that the prevention of poor bone health and fractures related to low bone mineral density can be achieved by the initiation of sound healthy behaviors early in life and continuing them throughout life. It is said that prevention is better than cure and these lines are fit for checking the occurrence of osteoporosis. Healthy diet along with regular physical activity or exercise like walking, aerobic exercise, yoga, swimming etc. through the early phase of life can be helpful in maintaining the bone health and counteract the risk of osteoporosis. Nutrition is one of the major determinants of osteoporosis along with physical activity and exercise. Calcium and vitamin D along with other nutrients like potassium, magnesium, ascorbic acid etc. can be taken either from diet or through supplementation. Dairy products are the best source of calcium, vitamin D and other nutrients. Except from diet Vitamin D can be produced endogenously through the action of sunlight. Vitamin D promotes calcium absorption and thereby enhances bone mineralization whereas other nutrients like potassium and magnesium acts like buffers and counteracts the leaching of nutrients from bones thus inhibit demineralization of bones.

\section{Introduction}

Menopause is a natural phenomenon which occurs among all women after the age of 4548 years at global level. According to Indian Menopause Society there are about sixty five million women above the age of forty five years in India. In developed countries the average age of menopause is about forty eight years but among Indian women it occurs between the ages of 30-35 years which is a very early age. The reason behind the early occurrence of this phenomenon in such developing countries is poor nutrition along with reduced level of physical activity. After menopause the bones health is highly affected. Poor bone health causes low bone mineral density which is also called as osteoporosis is a major public health problem around the world. As the age increases the risk of low 
bone mineral density along with various chronic diseases increase. After menopause the absorption of calcium along with cholecalciferol decreases. There are various reasons behind low absorption of calcium and vitamin $\mathrm{D}$. On one hand the reason behind occurrence of low bone mineral density is loss of female hormone estrogen after menopause which helps in the absorption of calcium and activation of the precursor of vitamin D and on other hand calcium, vitamin $\mathrm{D}$, magnesium, potassium, ascorbic acid and other nutrients deficient diet with sedentary life style. It causes morbidity and mortality associated with osteoporotic fractures like fracture of hip, spine, wrist, forearm etc. After menopause there is an average annual bone loss of $2-3 \%$ during the first few years and $0.5-1 \%$ thereafter.

Among such women the bone health can be maintained by including adequate intake of calcium, vitamin $\mathrm{D}$, ascorbic acid, protein, potassium, magnesium, etc. along with regular physical activities and weight bearing and other exercises like walking, swimming, running, dancing, swimming etc. According to European guidance, for the diagnosis and management of poor bone health among menopausal women over 50 years, they should take at least $1000 \mathrm{mg} /$ day, $800 \mathrm{IU} /$ day and $1 \mathrm{~g} / \mathrm{kg}$ body weight/day of calcium, vitamin D and protein receptively. Exercise and healthy diet like dairy products along with supplements of calcium, magnesium, potassium, iron etc. play a very important role in making a middle age women physically and psychologically fit. Physical exercise has been recognized beneficial for the health and wellbeing of all human beings especially middle aged women. During the transition of menopause and post menopause healthy diet and physical exercise both helps in energy balance in the body, helps in metabolism, reducing the weight gain, strengthens bones, maintaining healthier muscles, joints and bones, increases muscle mass and reduces the risk of stress, improve cognitive functioning and reduces the risk of chronic diseases like cancer, diabetes, heart diseases and degenerative and progressive diseases like osteoporosis among middle aged women. Regular exercise along with healthy diet containing adequate calcium, vitamin $\mathrm{D}$, protein, magnesium, ascorbic acid, etc which helps in improving muscle and bone strength and by preventing falls the risk of morbidity and mortality can be reduced. In this way such efforts can improves the quantity and quality of life of middle aged women of developed and developing countries.

\section{Materials and Methods}

The main purpose of the present study was to assess the awareness about maintenance of bone health through various dietary factors along with physical activity among middle aged women residing at selected urban community of eastern Uttar Pradesh. The study was conducted from December 2011 to March 2012. The sample from the selected urban community and the research design used for this study was non experimental designdescriptive survey method. The sample size selected for this study consisted of 100 urban women 50-60 years of age from selected urban community at Varanasi.

The respondents were selected randomly for the purpose of study. For the present study one hundred middle aged women were selected randomly from the urban area of Varanasi of Uttar Pradesh. The respondents were between the age group of 50-60 years, who were menopausal women, mostly home makers and were living sedentary life style. For collecting information regarding awareness about sitting in the sunlight, milk consumption, supplementary tablets and physical activity, questionnaire cum interview method technique was used during survey. 


\section{Results and discussion}

Information regarding views of respondents regarding frequency of sitting in the sunlight in the morning presented in Table 1. During the study it was found that majority $(57 \%)$ of the respondents were not sitting in the sunlight in the morning whereas only forty three percent respondents were sitting in the sunlight in the morning. Information regarding consumption of milk among respondents presented in Table 2. During the study it was found that majority of the respondents (72\%) were consuming milk, twenty percent were not consuming milk whereas eight percent respondents were consuming milk occasionally. Information regarding taking supplementary tablets by the respondents presented in Table 3. During the study it was found that only eleven percent respondents were taking supplementary tablets whereas majority $(75 \%)$ of the respondents was not taking supplementary tablets. Information regarding reduction in physical activity among respondents due to tiredness and weakness presented in Table 4.

Table.1 Views of respondents regarding sitting in the sunlight in the morning

\begin{tabular}{|c|c|c|}
\hline Responses & Frequency & Percentage \\
\hline Yes & 43 & 43 \\
\hline No & 57 & 57 \\
\hline Total & 100 & 100 \\
\hline
\end{tabular}

Table.2 Milk consumption of respondents

\begin{tabular}{|c|c|c|}
\hline Responses & Frequency & Percentage \\
\hline Yes & 72 & 72 \\
\hline No & 20 & 20 \\
\hline Occasionally & 8 & 8 \\
\hline Total & 100 & 100 \\
\hline
\end{tabular}

Table.3 Respondents taking supplementary tablets

\begin{tabular}{|c|c|c|}
\hline Responses & Frequency & Percentage \\
\hline Yes & 11 & 11 \\
\hline No & 75 & 75 \\
\hline Occasionally & 14 & 14 \\
\hline Total & 100 & 100 \\
\hline
\end{tabular}

Table.4 View of respondents about tiredness, weakness and reduced physical activity

\begin{tabular}{|c|c|c|}
\hline Responses & Frequency & Percentage \\
\hline Yes & 38 & 38 \\
\hline No & 50 & 50 \\
\hline Occasionally & 12 & 12 \\
\hline Total & 100 & 100 \\
\hline
\end{tabular}

During study it was found that there was fifty percent reduction in physical activity among respondents due to tiredness and weakness, thirty eight percent respondents were involved 
in physical activity whereas twelve percent respondents were involved in physical activity occasionally.

The conclusion of the study is that during study it was found that majority of the respondents were consuming milk but supplementation, sitting in the sunlight along with physical activity was ignored or neglected.

The prevalence of osteoporosis can be counteracted by creating more and more awareness among middle age women regarding consumption of nutrients through diet and supplementation.

Except intake of nutrients physical activity also plays a very important role.

\section{References}

Anderson, J.J.B., Rondano, P. and Holmes, A. 1996. Nutrition, Life Style and Quality of Life: Roles of Diet and Physical Activity in the Prevention of Osteoporosis. Department of Nutrition, Schools of Public Health and Medicine, University of North Carolina, at Chapel Hill, USA, 25(103): 65-74.

Berriche, O., Chiraz, A., Ben O.R., Souheila, H., Lahmer, Ines Wafa, C., Sebai, I., Sfar, H., Mahjoub, F. and Jamoussi, H. 2016. Nutritional risk factors for postmenopausal osteoporosis. Alexandria Journal of Medicine, 53: 187-192.

Chollet, M., Gille, D., Piccinali, P., Bütikofer, U., Schmid, A., Stoffers, H., Altintzoglou, T. and Walther, B. 2014. Short communication: Dairy consumption among middle-aged and elderly adults in Switzerland. Journal of Dairy Science,
97(9): 5387-5392.

Coupland, C.A.C., Cliffe, S.J., Bassey, E.J., Grainge, M.J., Hosking, D.J. and Chilversa, C.E.D. 1999. Habitual physical activity and bone mineral density in postmenopausal women in England. International Journal of Epidemiology, 28: 241-246.

Hardcastle, A.C., Aucott, L., Fraser, W.D., Reid, D.M. and Macdonald, H.M. 2011. Dietary patterns, bone resorption and bone mineral density in early postmenopausal Scottish women. European Journal of Clinical Nutrition, 65: 378385.

Macdonald, H.M., Black, A. J., Aucott, L., Duthie, G., Duthie, S., Sandison, R., Hardcastle A. C., New, S. A. L., Fraser, W. D. and Reid, D.M. 2008. Effect of potassium citrate supplementation or increased fruit and vegetable intake on bone metabolism in healthy postmenopausal women: a randomized controlled trial. American Journal of Clinical Nutrition, 88: 465-474.

Rizzoli, R., Ferrari, H. B., Hughes, B. D. and Weaver, C. 2014. Nutrition and bone health in women after the menopause. Womens Health, 10(6): 599-608.

Saravi, F.D. and Sayegh, F. 2013. Bone Mineral Density and Body Composition of Adult Premenopausal Women with Three Levels of Physical Activity. Journal of Osteoporosis, pp1-7.

Vijayalakshmi, S., Chandrababu, R. and Eilean V. L. 2013. Menopausal Transition among Northern Indian Women. Nitte University, Journal of Health Science, 3(2): 73-79.

\section{How to cite this article:}

Meenu Sirohi and Kalpna Gupta. 2018. A Study on Awareness of Bone Health among Middle Aged Women in Urban Area of Eastern Uttar Pradesh, India. Int.J.Curr.Microbiol.App.Sci. 7(01): 3216-3219. doi: https://doi.org/10.20546/ijcmas.2018.701.384 